\title{
Comparison of Flight Control System Design Methods in Landing
}

\author{
S.H. Sadati, M.Sabzeh Parvar and M.B. Menhaj \\ Aerospace Engineering Department, \\ Amir Kabir University, Hafez Ave., Tehran,
}

Iran

\section{Introduction}

The development and application of most present-day systems and control theory were spurred on by the need to resolve aerospace problems. This is roughly the problem of analyzing and designing flight control systems for tactical missiles or aircraft. The control laws used in current tactical missile or aircraft are mainly based on classical control design techniques. These control laws were developed in the 1950s and have evolved into fairly standard design procedures [1].

Current autopilot design processes contain time-and resource-consuming trial-and-error approaches. Especially late changes in the flight control laws contribute to high cost and delay of first delivery. The automatic landing mode development is a good example of a process with trial-and-error design phases, because of the many parameters the system has to be robust against. These parameters originate from different runway, terrain, ILS and weather characteristics, and from aircraft uncertainties like configuration and landing weight. Additional uncertainties arise from uncertain aerodynamic parameters, actuator model uncertainties, etc. The autonomous aircraft landing is an issue that implies three main aspects: the performance of equipment, the process models and the ethics. Generally, the landing is not a standard flight task as it could be thinking. We consider it a nonstandard flight stage because it has a very high sensitivity versus environment perturbation and to the psychological factors.

In the last three decades, optimality-based designs have been considered to be the most effective way for a guided missile engaging the target [2-4]. However, it is also known from the optimal control theory that a straightforward solution to the optimal trajectory shaping problem leads to a two point boundary-value problem [2], which is too complex for realtime onboard implementation. Based on the reasons given above, advanced control theory must be applied to a control system to improve its performance. One of the best ways to solve this problem is to approach the artificial intelligence modeling technology based on fuzzy logic and neural network [5].

Intelligent control is a control technology that replaces the human mind in making decisions, planning control strategies, and learning new functions whenever the environment does not allow or does not the presence of a human operator. Artificial neural networks and fuzzy logic are two potential tools for use in applications in intelligent control engineering. Artificial neural networks offer the advantage of performance improvement 
through learning by means of parallel and distributed processing. Many neural control schemes with back propagation training algorithms, which have been proposed to solve the problems of identification and control of complex nonlinear systems, exploit the nonlinear mapping abilities of neural networks [6,7]. Recently, adaptive neural network algorithms have also been used to solve highly nonlinear flight control problems. A fuzzy logic-based design that can resolve the weaknesses of conventional approaches has been cited above. The use of fuzzy logic control is motivated by the need to deal with highly nonlinear flight control and performance robustness problems. It is well known that fuzzy logic is much closer to human decision making than traditional logical systems. Fuzzy control based on fuzzy logic provides a new design paradigm such that a controller can be designed for complex, ill-defined processes without knowledge of quantitative data regarding the inputoutput relations, which are otherwise required by conventional approaches [8-11]. An overview of neural and fuzzy control designs for dynamic systems was presented by Dash et al.[12].

\section{Aircraft model}

Aircraft landing process enhanced several phases that define the so-called standard landing trajectory. The landing operation concerning two controlled maneuvers: first for guiding the aircraft in the horizontal plane, in order to align it onto the axe of the runway and the second, for aircraft guiding in the vertical plane in order to do the approaching of runway surface. Basically, the automatic landing systems provide the information for instrument navigation along the standard trajectory. In this paper only control about the longitudinal axis is considered. With this restriction, the equations of motion describing the aircraft take the form [13]:

$$
\begin{gathered}
\dot{V}=\frac{g}{W}\left(T_{b a l}-D\right)-g \sin \gamma \\
\dot{\gamma}=\frac{g}{V}\left(\frac{L}{W}-\cos \gamma\right) \\
\dot{q}=\frac{\bar{q} S C}{I_{y}}\left(C_{m}\right) \\
\dot{h}=V \sin \gamma \\
\dot{x}=V \cos \gamma \\
\dot{\theta}=q
\end{gathered}
$$

The state variables are $V=$ airspeed, $\gamma=$ flight path angle, $\theta=$ pitch angle, and $q=$ pitch rate, $h$ is the altitude, $T$ is the engine thrust force. The aerodynamic and propulsive forces are assumed to have the following form:

$$
C_{m}=C_{m_{0}}+C_{m_{q}} q+C_{m_{\alpha}} \alpha+C_{m_{\delta_{e}}} \delta_{e}+C_{m_{\delta_{f}}} \delta_{f}
$$




$$
\begin{gathered}
C_{L_{b a l}}=\frac{2 m g \cos \gamma_{g l}}{\rho S V_{l}^{2}} \\
\alpha_{b a l}=\frac{C_{L_{b}}-C_{L_{0}}}{C_{L_{\alpha}}} \\
T_{b a l}=C_{D\left(C_{L_{b a l}}\right)} \frac{\rho V_{l}^{2} S}{2}+m g \sin \gamma_{g l} \\
\delta_{b a l}=-\left(C_{m_{0}}+C_{m_{\alpha}} \alpha_{b a l}+C_{m_{\delta_{f}}} \delta_{f}\right) / C_{m_{\delta_{e}}} \\
C_{L}(\alpha)=\left\{\begin{array}{l}
C_{D}(\alpha)=B_{0}+B_{1} \alpha+B_{2} \alpha^{2} \\
C_{0}+C_{1} \alpha+C_{2} \alpha^{2},
\end{array}\right\},\left\{\begin{array}{l}
\alpha \leq \alpha * \\
\alpha^{*} \leq \alpha \leq \alpha_{\max }
\end{array}\right\}
\end{gathered}
$$

The model parameter data given in Table 1 refer to a Boeing B727 aircraft powered by three JT8D-17 turbofan engines [13].

\section{Conventional design methods}

Generally, the controller is in a form of proportional-integral-derivative (PID) parameters, and the control gains are determined by using classical control theory, such as the root locus method, Bode method or Nyquist stability criterion [14-16]. Modern control theory has been used extensively to design the flight control system, such as in the linear quadratic techniques [17,18], generalized singular linear quadratic technique [19], $H_{\infty}$ design technique and $\mu$ synthesis technique [20].

\section{A. Optimal Control}

The optimization of dynamic processes frequently requires the solution of an optimal control problem. That is, given a process model in terms of differential equations for the state variables, find the vector of control functions that minimizes some performance index, subject to boundary conditions and possibly additional equality or inequality constraints on the state and controls. Application of the necessary condition for optimal control of systems defined by ordinary differential equations results in a two-point boundary value problem. A suitable Method to solve such problems is the well-known Multiple Shooting Method [21]. The method reduces the boundary value problem to the solution of a set of algebraic equations and initial value problems with partially unknown initial conditions that are solve by Newton iteration. Based upon this method, this boundary value problem is solved numerically by the Multiple Shooting code BNDSCO [22]. The optimal trajectory problem consists of minimizing [2]

$$
J(u)=\int\left[\left(\delta_{e}-\delta_{e_{b a l}}\right)^{2}+\left(H^{*}-H\right)^{2}\right] d t
$$

with boundary conditions are, 


$$
\begin{aligned}
& V(0)=V_{0}, \\
& \gamma(0)=\gamma_{0}, \\
& q(0)=q_{0} \\
& h(0)=h_{0}, h\left(t_{f}\right)=h_{f} \\
& X(0)=X_{0} \\
& \theta(0)=\theta_{0,}, \theta\left(t_{f}\right)=\theta_{f}
\end{aligned}
$$

and the final time $t_{f}$ is free

The variational Hamiltonian is formed by adjoining the right-hand sides of the system of state differential Eqs. (1-6) with the costate variables

$$
\begin{aligned}
& H=\left(\delta_{e}-\delta_{e_{b}}\right)^{2}+\left(H^{*}-H\right)^{2}+ \\
& \lambda_{V}\left(\frac{g}{W}\left(T_{b}-D\right)-g \sin \gamma\right)+\lambda_{\gamma}\left(\frac{g}{V}\left(\frac{L}{W}-\cos \gamma\right)\right) \\
& +\lambda_{q}\left(\frac{\bar{q} S C}{I_{y}} C_{m}\right)+\lambda_{h}(V \sin \gamma)+\lambda_{x}(V \cos \gamma)+\lambda_{\theta}(q)
\end{aligned}
$$

The costate variables are defined by differential equation

$$
\begin{gathered}
\frac{d \lambda_{v}}{d t}=-\frac{\partial H}{\partial v}, v=V, \gamma, q, h, x, \theta \\
\dot{\lambda}_{V}=\lambda_{V}\left[\frac{g}{W}\left(D_{v}\right)\right]+\lambda_{\gamma} \frac{g}{V^{2}}\left(\frac{L}{W}-\cos \gamma\right)-\lambda_{q} \frac{\bar{q}_{v} C S C_{m}}{I_{y}}-\lambda_{h} \sin \gamma-\lambda_{x} \cos \gamma \\
\dot{\lambda}_{\gamma}=\lambda_{V} g \cos \gamma-\lambda_{\gamma} \frac{g \sin \gamma}{V}-\lambda_{h} V \cos \gamma+\lambda_{x} V \sin \gamma \\
\dot{\lambda}_{q}=-\lambda_{q} \frac{\bar{q} C S C_{m_{q}}}{I_{y}}-\lambda_{\theta} \\
\dot{\lambda}_{h}=2\left(H^{*}-H\right) \\
\dot{\lambda}_{x}=0 \\
\dot{\lambda}_{\theta}=0
\end{gathered}
$$

Solving these equations with the appropriate boundary conditions is a two-point boundaryvalue problem (TPBVP). Generally, at the initial point, all six states are specified and the costates are free; whereas, at the final time, the $H, \theta$ is fix and the remaining four states are free. Thus, at the final time all costates are free. The free final time $t_{f}$ can be considered as an additional variable of the problem and, by the standard transformation

$$
t=t_{f} \xi
$$




$$
d / d \xi=t_{f} d / d t
$$

The equations are transformed into a system with the independent variable $\xi$ ranging in the interval $0 \leq \xi \leq 1$. Further, the additional trivial differential equation

$$
\frac{d}{d \xi} t_{f}=0
$$

is added to the system. At the final time, the transversality condition requires that

$$
H\left(t_{f}\right)=0
$$

The optimal control function is obtained by means of the minimum principle. With respect to the elevator, we find the relation

$$
\delta_{e}=\delta_{e_{b}}-\lambda_{q} \frac{\bar{q} \operatorname{CSC}_{m_{\delta_{e}}}}{2 I_{y}}
$$

Result of optimal trajectory for the selected B-727 is presented in Fig (3) through (8). The costate variable $\lambda_{q}$, which is responsible for the determination of the extermal controller, is shown in Fig.8.

\section{B. Pole Placement Method}

An alternative and very powerful method for designing feedback gains for autostabilization systems is the pole placement method. The method is based on the manipulation of the equations of motion in state space form and makes full use of the appropriate computational tools in the analytical process. Practical application of the method to airplanes is limited since it assumes that all state variables are available for use in an augmentation system, which is not usually the case. The open loop state equation may then be written

$$
\dot{\mathrm{X}}=\mathrm{AX}+\mathrm{BU} \& \mathrm{Y}=\mathrm{CX}
$$

$$
\mathrm{A}=\left[\begin{array}{ccccc}
-0.04436 & 29.988 & 0 & -32.1629 & 0 \\
-0.001458 & -0.53075 & 1 & 0.007357 & 0 \\
0 & -0.4914 & -0.431 & 0 & 0 \\
0 & 0 & 1 & 0 & 0 \\
0 & -210 & 0 & 210 & 0
\end{array}\right] \& \mathrm{~B}=\left[\begin{array}{c}
0 \\
0 \\
-0.5849 \\
0 \\
0
\end{array}\right]
$$

To track the target successfully, the closed-loop tracking system must be fast enough. To improve the flying qualities of this airplane more short-period damping is needed. A short period mode damping ratio of 0.7 was chosen to have gives a good margin of stability. Therefore, the pole placement method is employed to give the augmented aircraft the following closed loop characteristic polynomial

$\Delta_{\text {aug }}(s)=(s+0.00019)\left(s^{2}+11.2 s+64\right)\left(s^{2}+0.12 s+0.0684\right)$. The feedback gain matrix required to give the augmented aircraft the characteristic polynomial was determined $\mathrm{K}=\left[\begin{array}{lllll}0.1411 & -85.6292 & -17.6339 & -14.6896 & -0.0004\end{array}\right]$ 


\section{Intelligent control techniques}

Intelligent control achieves automation via the emulation of biological intelligence. It either seeks to replace a human who performs a control task or it borrows ideas from how biological systems solve problems and applies them to the solution of control problems. In this section we will provide an overview of several techniques used for intelligent control and discuss challenging industrial application domains where these methods may provide particularly useful solutions. The objective here is not to provide a comprehensive treatment. We only seek to present the basic ideas to give a favor of the approaches.

\section{A. Neural Net-based Control Design}

Artificial neural networks are circuits, computer algorithms, or mathematical representations loosely inspired by the massively connected set of neurons that form biological neural networks. The success of neural networks is mainly attributed to their unique features:

1. Parallel structures with distributed storage and processing of massive amounts of information.

2. Learning ability made possible by adjusting the network interconnection weights and biases based on certain learning algorithms.

The neural flight control architecture is based upon the augmented model inversion controller, developed by Rysdyk and Calise [23]. The NN adaptation rule results from nonlinear stability analysis, which ensures that the error signals and network weights are bounded. One of the common methods for controlling nonlinear dynamical systems is based on approximate feedback linearization [24]. The form that is employed in each control channel depends on the relative degree of the controlled variable. To simplify our discussion, we assume that the system has full relative degree, where each controlled variable (element of the state vector $x$ ) has a relative degree of two

$$
\ddot{x}=f(x, \dot{x}, \delta)
$$

In the case of aircraft, typically $x, \delta \in R$, where the element of $x$ correspond to the pitch attitude angle. A variant of this form arises in which angular rate is controlled. Here, the equation of motion for that degree of freedom is expressed in first order form [25]. A pseudo-control $\mathrm{v}$ is defined such that the dynamic relation between it and the system state is linear

$$
v=f(x, \dot{x}, \delta)
$$

Ideally, the actual controls $\delta$ are obtained by inverting Eq. (30). The total pseudo control signal is constructed of three components

$$
v=v_{r m}+v_{p d}-v_{a d}
$$

where $v_{r m}$ the pseudo-control component is generated by the reference model, $v_{p d}$ is the output of the linear compensator, and $v_{a d}$ is generated by the adaptive element introduced to compensate for the model inversion error. The linear compensator is designed so that the error dynamics are stabilized. This is most often achieved using standard proportionalderivative (PD) controllers, although additional integral action can be incorporated to improve steady state performance. For the second order system, PD compensation is expressed by 


$$
v_{p d}=\left[\begin{array}{ll}
K_{P} & K_{D}
\end{array}\right] e
$$

The compensator gain matrices $K_{P}, K_{D} \in R$ are chosen so that the tracking error dynamics given by

$$
\begin{gathered}
\dot{e}=A e+B\left[v_{a d}-\Delta\right] \\
A=\left[\begin{array}{cc}
0 & I \\
-K_{P} & -K_{D}
\end{array}\right], B=\left[\begin{array}{l}
0 \\
I
\end{array}\right]
\end{gathered}
$$

are stable, i.e., the eigenvalues of $A$ are prescribed. It is evident from Eq. (33) that the role of the adaptive component $v_{a d}$ is to cancel $\Delta$.The adaptive signal is chosen to be the output of a single hidden layer [26].

$$
v_{a d}=W^{T} \sigma\left(V^{T} \bar{x}\right)
$$

where $V$ and $W$ are the input and output weighting matrices, respectively, and $\sigma$ is a sigmoid activation function. Although ideal weighting matrices are unknown and usually cannot be computed, they can be adapted in real time using the following NN weights training rules [27]:

$$
\begin{gathered}
\dot{W}=-\left[\left(\sigma-\sigma^{\prime} V^{T} \bar{x}\right) e^{T} P B+\kappa\|e\| W\right] \Gamma_{W} \\
\dot{V}=-\Gamma_{V}\left[\bar{x} e^{T} P B W^{T}+\kappa\|e\| V\right]
\end{gathered}
$$

where $\Gamma_{W}, \Gamma_{V}$ and $\Gamma_{W}, \Gamma_{V}$ are the positive definite learning rate matrices, and $\mathrm{K}$ is the emodification parameter. Here, $P$ is a positive definite solution of the Lyapunov equation $A^{T} P+P A+Q=0$ for any positive definite $Q$.

\section{B. Fuzzy Logic-Based Control Design}

The existing applications of fuzzy control range from micro-controller based systems in home applications to advanced flight control systems. The main advantages of using fuzzy are as follows:

1. It is implemented based on human operator's expertise which does not lend itself to being easily expressed in conventional proportional integral-derivative parameters of differential equations, but rather in action rules.

2. For an ill-conditioned or complex plant model, fuzzy control offers ways to implement simple but robust solutions that cover a wide range of system parameters and, to some extent, can cope with major disturbances.

The aircraft landing procedures admit a linguistic describing. This is practiced, for example, in case of guiding for landing in non-visibility conditions or in piloting learning. This approach permits to build a model for landing control based on the reasoning rules using the fuzzy logic. The process requires the control of the following parameters: the current altitude to runway surface $(H)$, the aircraft's vertical speed and aircraft flight speed. The goal of the control is formulated as follow: the aircraft should touch the runway ( $H$ becomes 0$)$ at the conventional point of landing with admitted vertical touch speed and the recommended 
landing speed. The input of FLC normally includes the error between the state variable and its set point, $\left(e=x_{d}-x\right)$ and the first derivative of the error, $\dot{e}$. A typical form of the linguistic rules is represented as

Rule $\mathrm{i}$ Th: If $e$ is $A_{i}$ and $\dot{e}$ is $B_{i}$ then $u^{*}$ is $C_{i}$

Where $A_{i}, B_{i}$, and $C_{i}$ are the fuzzy sets for the error, the error rate, and the controller output at rule $\mathrm{i}$, respectively, and $\mathrm{u}^{*}$ is the controller output.

The resulting rule base of FLC is shown in Table 2. The abbreviations representing the fuzzy sets $\mathbf{N}, \mathbf{Z}, \mathbf{P}, \mathbf{S}$, and $\mathbf{B}$ in linguistic form stand for negative, zero, positive, small, and big, respectively, for example negative big (NB). Five fuzzy sets in triangular membership functions are used for FLC input variables, e and è, and FLC output, u* For the fuzzy inference or rule firing, Mamdani-type min-max composition is employed. In the defuzzification stage, by adopting the method of center of gravity, the deterministic control $u$ is obtained. The membership functions have been designed for input and output diagram using the trapezoidal shapes, as shown in Figures 1, 2. The fuzzy control system design with a simple longitudinal aircraft model given by Eqs. (1-6).

\section{Advantages over Conventional Designs}

1. Fuzzy guidance and control provides a new design paradigm such that a control mechanism based on expertise can be designed for complex, ill-defined flight dynamics without knowledge of quantitative data regarding the input-output relations, which are required by conventional approaches. A fuzzy logic control scheme can produce a higher degree of automation and offers ways to implement simple but robust solutions that cover a wide range of aerodynamic parameters and can cope with major external disturbances.

2. Artificial Neural networks constitute a promising new generation of information processing systems that demonstrate the ability to learn, recall, and generalize from training patterns or data. This specific feature offers the advantage of performance improvement for ill-defined flight dynamics through learning by means of parallel and distributed processing. Rapid adaptation to environment change makes them appropriate for guidance and control systems because they can cope with aerodynamic changes during flight.

\section{Simulation results and discussion}

Simulations are performed at sea level, airspeed of $210 \mathrm{ft} / \mathrm{s}$, corresponding to the flare maneuver configuration of the Boeing 727. The simulation results are presented in Figs 3 to 8. Figure 3, which depicts the flight speed variation, demonstrates that the engines can regulate slight speed until that is compromised for attitude rate control. Time histories of the controls are shown in Fig. 4. The time response of pitch angle is shown in fig.5. A comparison between the commanded altitude profile and the actual aircraft response is presented in Fig. 6, it shows that the difference between the actual and desired trajectory (the fuzzy logic, neural net-based adaptive and optimal controls) is kept less than about $6 \mathrm{ft}$. This figure, so shows that the sink rate (the rate of descent) is reduced to less than $1.0 \mathrm{ft} / \mathrm{sec}$, which is small enough to achieve a smooth landing. The fuzzy logic, neural net-based adaptive and optimal control approaches do the flare maneuver well, while the Pole Placement Method has substantially large error. Neural network adaptation signal $v_{a d}$ for compensate inversion error is presented in Fig. 7. Summarizing the results presented so far, the nonlinear controller performance for this maneuver has been found very good. 


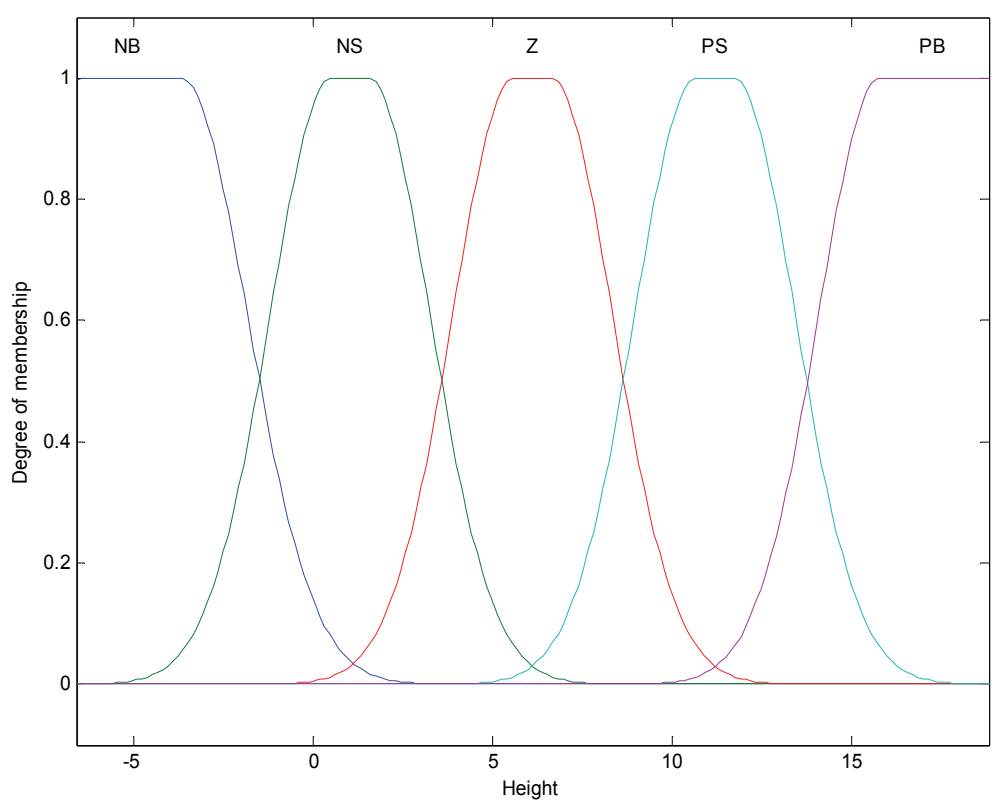

Fig. 1. Altitude Membership Functions

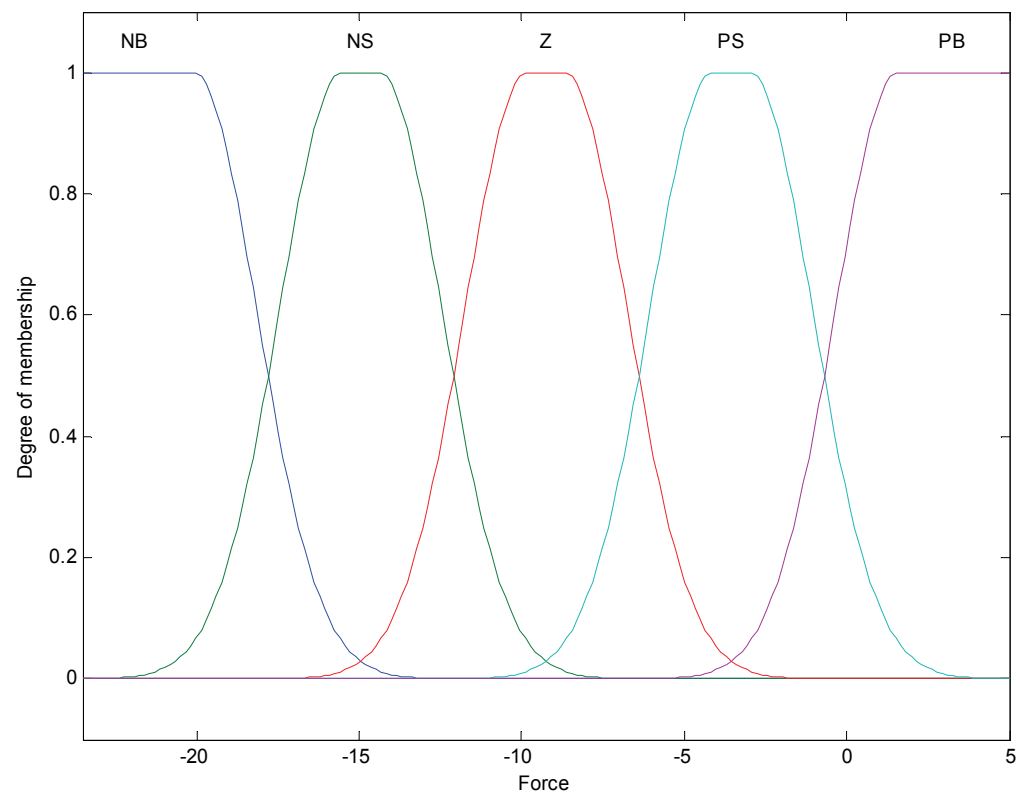

Fig. 2. Force Membership Functions 


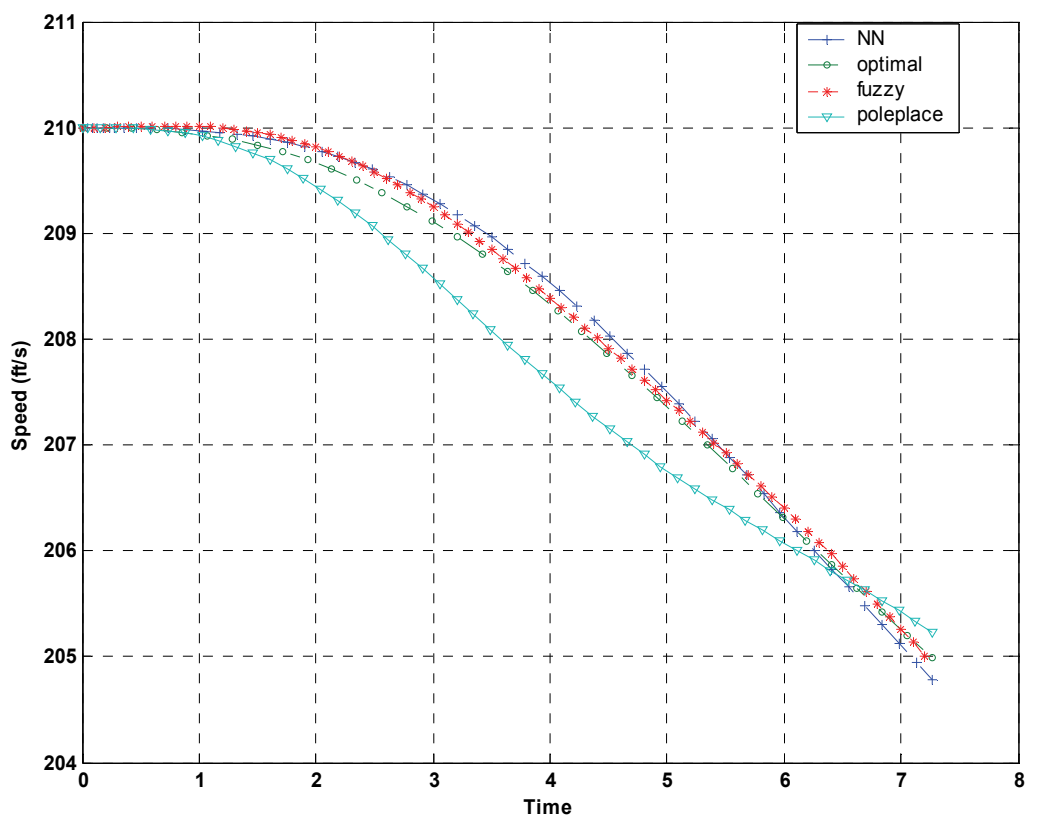

Fig. 3. Time response of the airspeed

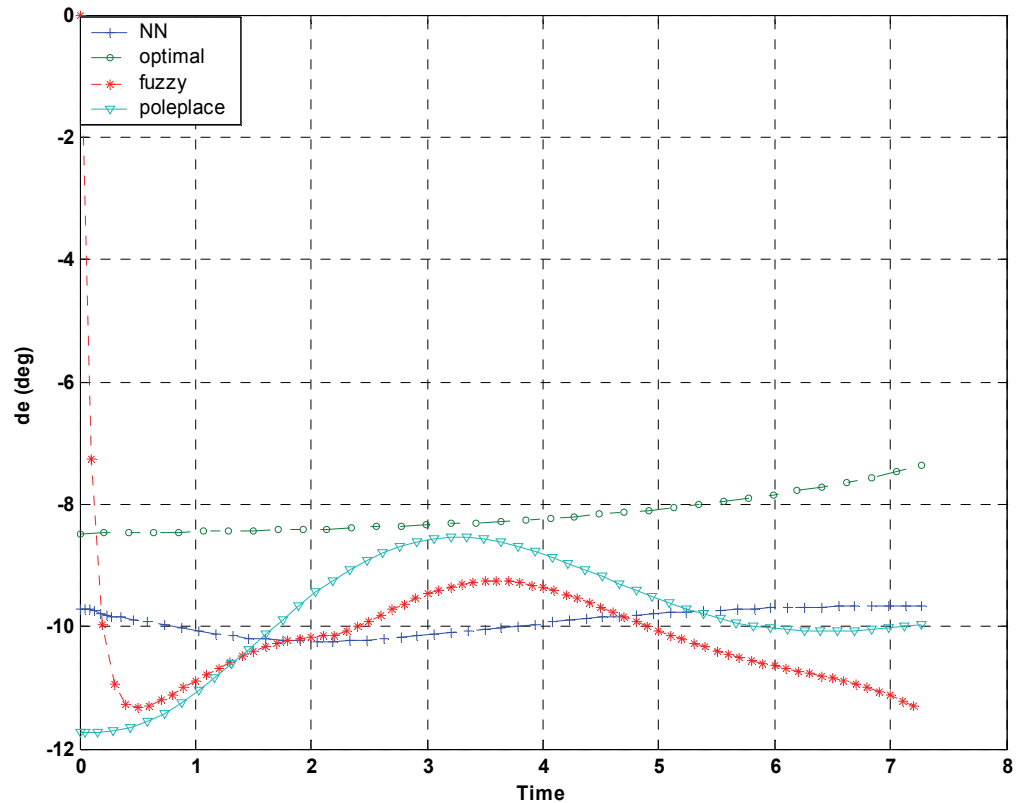

Fig. 4. Time response of the elevator 


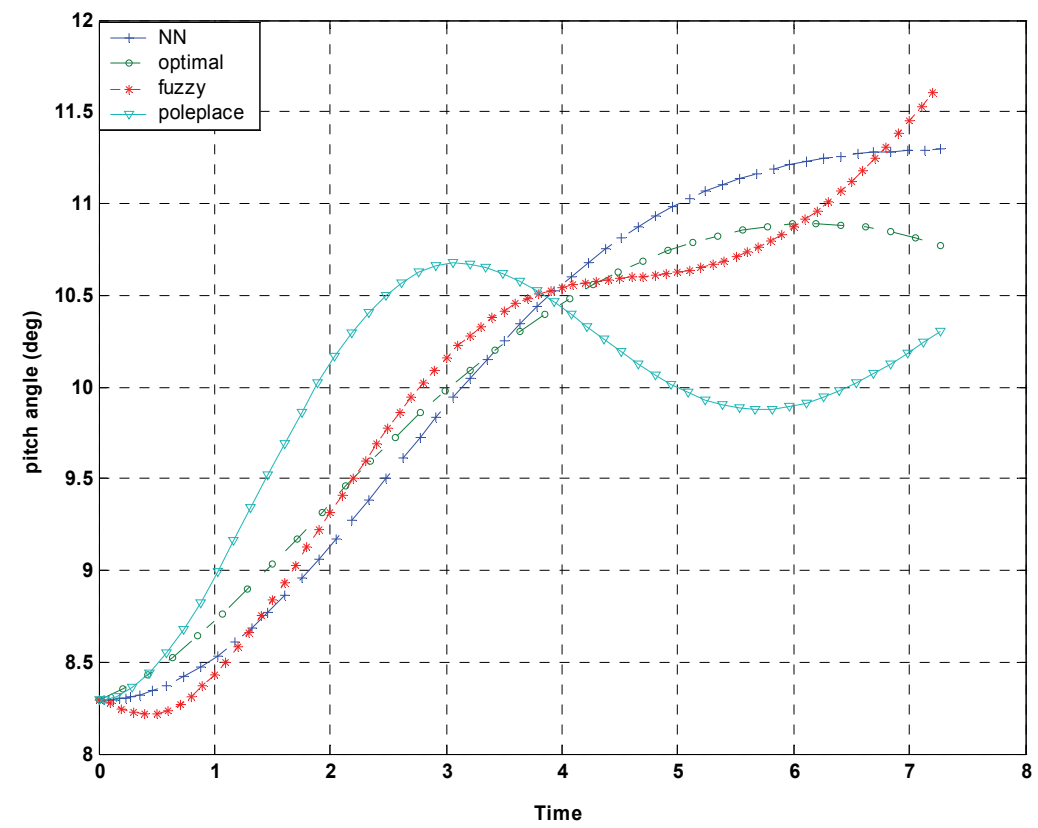

Fig. 5. Time response of the pitch angle

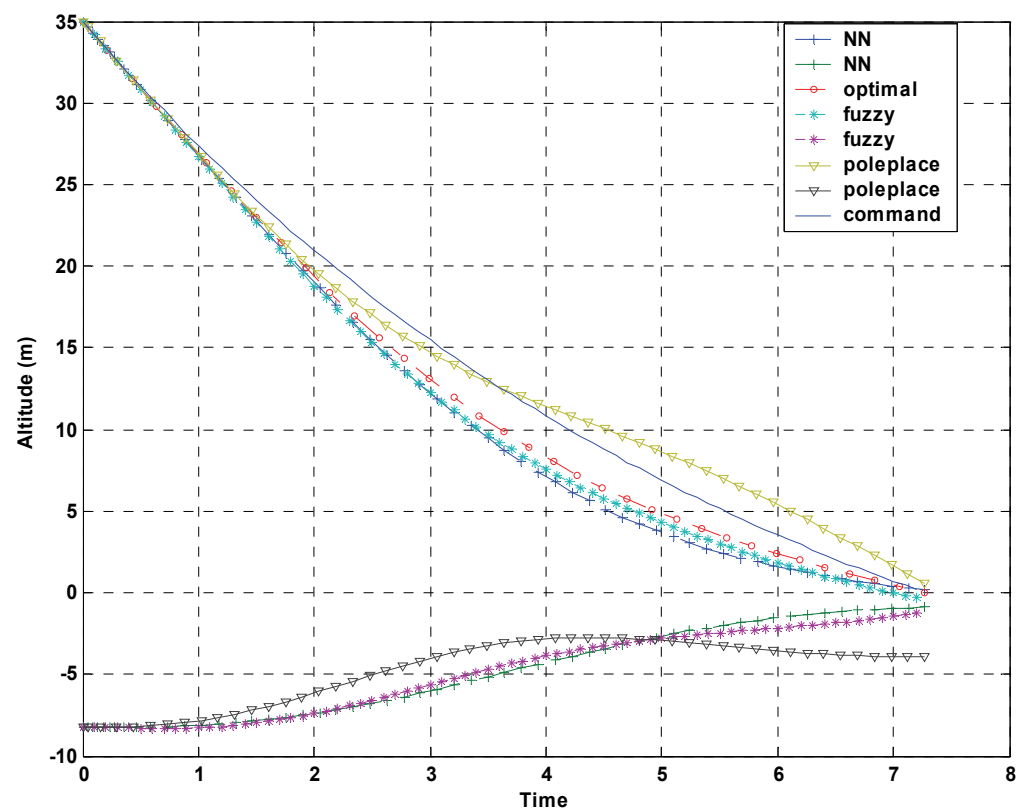

Fig. 6. Desired and actual flare trajectories 


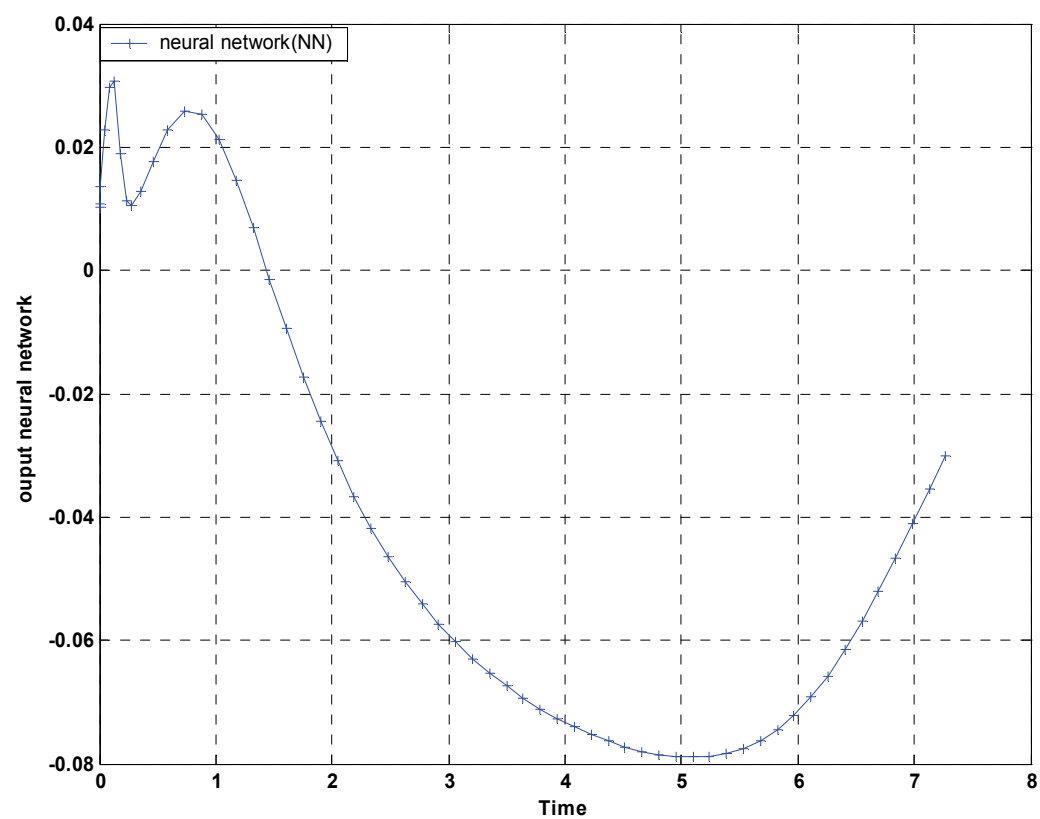

Fig. 7. NN adaptation signal $v_{a d}$

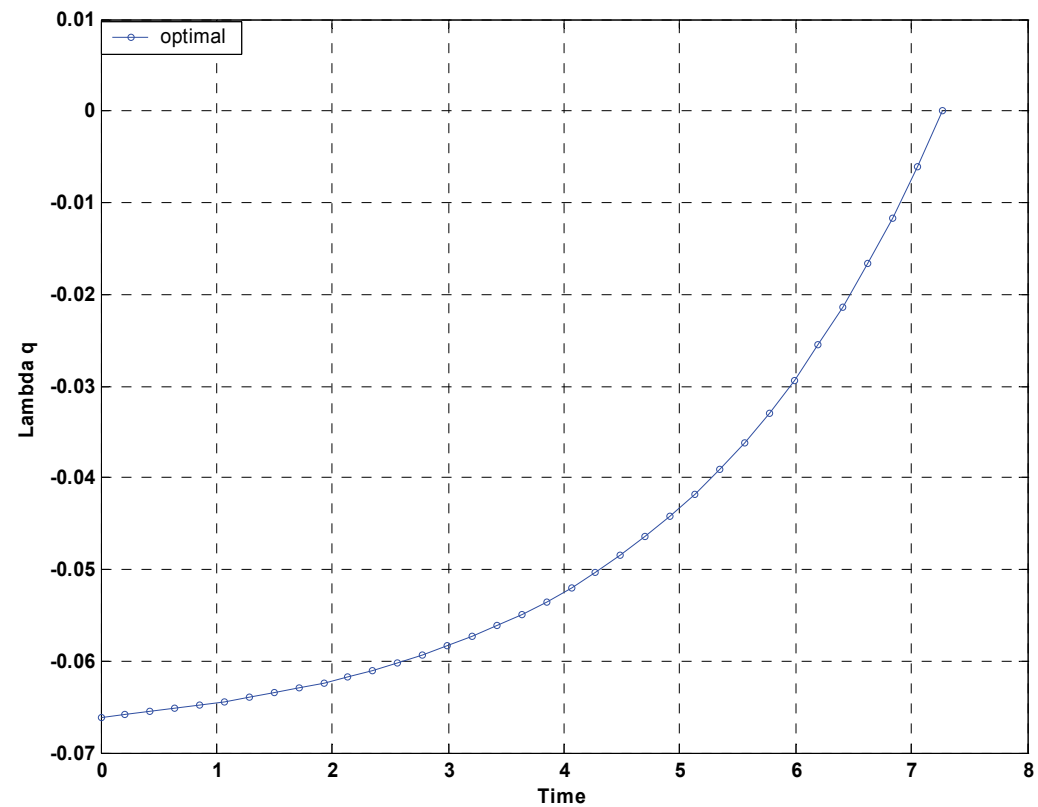

Fig. 8. Time response of the $\lambda_{q}$ 


\section{Conclusions}

It has been the general focus of this paper to summarize the basic knowledge about intelligent control structures for the development of control systems. For completeness, conventional, adaptive neural net-based, fuzzy logic-based, control techniques have been briefly summarized. Our particular goal was to demonstrate the potential intelligent control systems for high precision maneuvers required by aircraft landing. The proposed model reveals the functional aspect for realistic simulation data. The method does not require the existing controller to be designed based on a linear model.

\begin{tabular}{|c|c|}
\hline $\mathrm{a}_{\max }=17.2$ & $\mathrm{a}_{*}=12 \mathrm{deg}$ \\
\hline $\mathrm{g}=32.2 \mathrm{ft}^{2}$ & $\mathrm{I}_{\mathrm{y}}=3 \times 10^{6}$ \\
\hline $\mathrm{C}_{0}=0.7125$ & $\mathrm{~B}_{0}=0.1552$ \\
\hline $\mathrm{B}_{1}=0.12369 \mathrm{rad}^{-1}$ & $\mathrm{~S}=0.156 \times 10^{4} \mathrm{ft}^{2}$ \\
\hline $\mathrm{B}_{2}=2.4203 \mathrm{rad}^{-2}$ & $\mathrm{~W}=150000 \mathrm{Ib}$ \\
\hline $\mathrm{C}_{2}=-9.0277 \mathrm{rad}^{-2}$ & $\mathrm{C}_{1}=6.0877 \mathrm{rad}^{-1}$ \\
\hline
\end{tabular}

Table 1. model parameter data B-727

\begin{tabular}{|c|c|c|c|c|c|}
\hline \multicolumn{7}{|c|}{ Fuzzy set, $\dot{e}$} \\
\hline Fuzzy set, $\boldsymbol{e}$ & NB & NS & Z & PS & PB \\
\hline NB & PB & PB & PS & PS & NS \\
\hline NS & PB & PS & PS & NS & NB \\
\hline Z & PB & PS & Z & NS & NB \\
\hline PS & PB & PS & NS & NS & NB \\
\hline PB & PS & NS & NS & NB & NB \\
\hline
\end{tabular}

Table 2. Rule base for FLC

\section{References}

[1] Chicago, IL, U.S.A. Locke, A. S., Guidance, D. Van Nostrand Co., Princeton, NJ, U.S.A (1955).

[2] Bryson, A. E., Jr. and Y. C. Ho, Applied Optimal Control., Blaisdell, Waltham, MA, U.S.A (1969).

[3] Lin, C. F., Modern Navigation, Guidance, and Control Processing, Prentice-Hall, Englewood Cliffs, NJ, U.S.A (1991).

[4] Zarchan, P., Tactical and Strategic Missile Guidance, 2nd Ed., AIAA, Inc., Washington, D.C., U.S.A (1994).

[5] Bezdek, J., "Fuzzy Models: What are they and Why," IEEE Trans. Fuzzy Syst., Vol.1 No.1, pp, 1-6 (1993).

[6] Miller, W. T., R. S. Sutton, and P. J. Werbos., Neural Networks for Control., MIT Press, Cambridge, MA, U.S.A. Mishra (1991).

[7] Narendra, K. S. and K. Parthasarthy., Identification and control of dynamical systems using neural networks. IEEE Trans. Neural Networks, 1(1), 4-27 (1990). 
[8] Mamdani, E. H. and S. Assilian., An experiment in linguistic synthesis with a fuzzy logic controller. Int. J. Man Machine Studies, 7(1), 1-13 (1975).

[9] Lee, C. C., Fuzzy logic in control systems: fuzzy logic controller part I. IEEE Trans. Syst. Man and Cyb., 20(2), 404-418 (1990).

[10] Lee, C. C., Fuzzy logic in control systems: fuzzy logic controller part II. IEEE Trans. Syst. Man and Cyb., 20(2), 419-435 (1990).

[11] Driankov, D., H. Hellendoorn, and M. Reinfrank., "An Introduction to Fuzzy Control". Springer, Berlin, Germany. Driankov (1993).

[12] Dash, P. K., S. K. Panda, T. H. Lee and J. X. Xu., Fuzzy and neural controllers for dynamic systems: an overview. Proc. Int. Conf. Power Electronics, Drives and Energy Systems, Singapore (1997).

[13] BULIRSCH,R., F. Montone, and H. Pesch, "Abort Landing in the Presence of Windshear as a minimax optimal Control Problem, Part 1: Necessary Conditions", J. Opt. Theory Appl., Vol. 70,pp. 1-23 (1991).

[14] Price, C. F. and R. S. Warren, "Performance Evaluation of Homing Guidance Laws for Tactical Missiles," TASC Tech (1973).

[15] Nesline, F. W., B. H. Wells, and P. Zarchan, "Combined optimal/classical approach to robust missile autopilot design," AIAA J. Guid. Contr., Vol.4,No.3, pp.316-322 (1981).

[16] Nesline, F.W. and M.L. Nesline, "How Autopilot Requirements Constrain the Aerodynamic Design of Homing Missiles," Proc. Amer. Contr. Conf., San Diego, CA, USA, pp.176-730 (1984).

[17] Stallard, D. V., "An Approach to Autopilot Design for Homing Interceptor Missiles," AIAA Paper 91-2612, AIAA, Washington, D.C., U.S.A, pp. 99-113 (1991).

[18] Lin, C.F., J. Cloutier, and J. Evers, "Missile Autopilot Design Using a Generalized Hamiltonian Formulation," Proc. IEEE 1st Conf. Aero. Contr. Syst., Westlake Village, CA, USA, pp. 715-723 (1993).

[19] Lin, C. F. and S. P. Lee, "Robust missile autopilot design using a generalized singular optimal control technique," J. Guid., Contr., Dyna., Vol. 8, No. 4, pp. 498-507 (1985).

[20] Lin, C. F. Advanced Control System Design. Prentice- Hall, Englewood Cliffs, NJ, U.S.A (1994).

[21] Stoer J. and R. Burlisch, Introduction to Numerical Analysis, Springer Verlag, New York, (1980).

[22] Oberle, H.J, "BNDSCO-A Program for the Numerical Solution of Optimal Control Problems," Internal Report No.515-89/22, Institute for Flight Systems Dynamics, DLR, Oberpfaffenhofen, Germany (1989).

[23] Rysdyk, R., B. Leonhardt, and A.J. Calise, “Development of an Intelligent Flight Propulsion Control System: Nonlinear Adaptive Control," AIAA- 2000-3943, Proc. Guid. Navig. Contr. Conf., Denver, CO, USA (2000).

[24] Isodori, A., Nonlinear Control Systems, Springer Verlag, Berlin (1989).

[25] Calise, A. J., S. Lee, and M. Sharma, "Development of a reconfigurable flight control law for the X-36 tailless fighter aircraft," Proc. AIAA Guid. Navig. Contr. Conf., Denver, CO, USA., AIAA-2000-3940 (2000).

[26] Hornik, K., M. Stinchcombe, M. and H. White, "Multilayer Feedforward Networks are Universal Approximators," Neural Networks, Vol. 2, pp. 359-366 (1989).

[27] Johnson, E. and A.J. Calise, "Neural Network Adaptive Control of Systems with Input Saturation," Proc. Amer. Contr. Conf., pp. 3527-3532. (2001). 


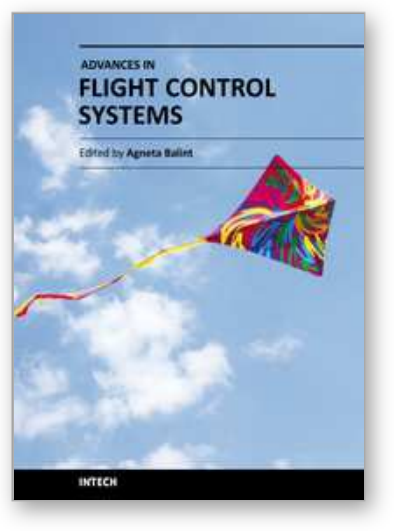

\author{
Advances in Flight Control Systems \\ Edited by Dr. Agneta Balint
}

ISBN 978-953-307-218-0

Hard cover, 296 pages

Publisher InTech

Published online 11, April, 2011

Published in print edition April, 2011

Nonlinear problems in flight control have stimulated cooperation among engineers and scientists from a range of disciplines. Developments in computer technology allowed for numerical solutions of nonlinear control problems, while industrial recognition and applications of nonlinear mathematical models in solving technological problems is increasing. The aim of the book Advances in Flight Control Systems is to bring together reputable researchers from different countries in order to provide a comprehensive coverage of advanced and modern topics in flight control not yet reflected by other books. This product comprises 14 contributions submitted by 38 authors from 11 different countries and areas. It covers most of the currents main streams of flight control researches, ranging from adaptive flight control mechanism, fault tolerant flight control, acceleration based flight control, helicopter flight control, comparison of flight control systems and fundamentals. According to these themes the contributions are grouped in six categories, corresponding to six parts of the book.

\title{
How to reference
}

In order to correctly reference this scholarly work, feel free to copy and paste the following:

S.H. Sadati, M.Sabzeh Parvar and M.B. Menhaj (2011). Comparison of Flight Control System Design Methods in Landing, Advances in Flight Control Systems, Dr. Agneta Balint (Ed.), ISBN: 978-953-307-218-0, InTech, Available from: http://www.intechopen.com/books/advances-in-flight-control-systems/comparison-of-flightcontrol-system-design-methods-in-landing

\section{INTECH}

open science | open minds

\section{InTech Europe}

University Campus STeP Ri

Slavka Krautzeka 83/A

51000 Rijeka, Croatia

Phone: +385 (51) 770447

Fax: +385 (51) 686166

www.intechopen.com

\section{InTech China}

Unit 405, Office Block, Hotel Equatorial Shanghai

No.65, Yan An Road (West), Shanghai, 200040, China

中国上海市延安西路65号上海国际贵都大饭店办公楼 405 单元

Phone: +86-21-62489820

Fax: $+86-21-62489821$ 
(C) 2011 The Author(s). Licensee IntechOpen. This chapter is distributed under the terms of the Creative Commons Attribution-NonCommercialShareAlike-3.0 License, which permits use, distribution and reproduction for non-commercial purposes, provided the original is properly cited and derivative works building on this content are distributed under the same license. 